\title{
Oxidation of Alcohols with Potassium Chlorochromate
}

\author{
Per H. J. Carlsen* and Jon Erik Brænden \\ University of Trondheim, The Norwegian Institute of Technology, Institute of Organic Chemistry, \\ N-7034 Trondheim-NTH, Norway
}

\begin{abstract}
Carlsen, P. H. J. and Brænden, J. E., 1987. Oxidation of Alcohols with Potassium Chlorochromate. - Acta Chem. Scand., Ser. B 41: 313-317.

Potassium chlorochromate, $\mathrm{KCrClO}_{3},(\mathrm{KCC})$ is a versatile and inexpensive oxidation reagent. It converts secondary saturated, as well as allylic and benzylic alcohols to the corresponding carbonyl compounds in high yields in a variety of solvents, preferentially acetone. The reagent is highly selective. Thus, oxidation of primary alcohols gives aldehydes as the exclusive products. KCC is less useful for the transformation of primary saturated and homoallylic alcohols. Double bonds are susceptible to isomerization under the reaction conditions employed; for example, oxidation of pure nerol yields citral, and pulegol is converted to a mixture of pulegone and isopulegone. Oxidation of tertiary allylic alcohols may give the transposed aldehyde. Thus, linalool is converted to citral in high yield.
\end{abstract}

Chromium(VI) reagents are highly valuable oxidizing agents in organic chemistry. ${ }^{1}$ In the past, chromic acid and chromium trioxide in a variety of solvents, for example acetone (Jones' reagent $),{ }^{2}$ and chromium(VI) reagents with heterocyclic bases, for example the chromium trioxidepyridine complex (Sarett's ${ }^{3}$ and Collin's ${ }^{4}$ reagents) have found widespread application for the oxidation of primary and secondary alcohols to the corresponding carbonyl compounds. More recently, pyridinium chlorochromate $(\mathrm{PCC})^{5}$ and pyridinium dichromate (PDC) ${ }^{6}$ were introduced by Corey and have rapidly become the reagents most widely used for oxidation of alcohols. A variety of related heterocyclic bases also form salts with chromic acid and chlorochromic acid, many of which are selective reagents for oxidation of alcohols to carbonyl compounds. Typical reagents are 4-( $\mathrm{N}, \mathrm{N}$-dimethylamino)-pyridine chlorochromate, ${ }^{7}$ tetrabutylammonium chlorochromate, ${ }^{8}$ nicotine dichromate, ${ }^{9} 2,2^{\prime}$-bipyridinium chlorochromate, ${ }^{10}$ triethylammonium chlorochromate, ${ }^{11}$ benzyltriethylammonium dichromate, ${ }^{12}$ pyridinium silver dichromate, ${ }^{13}$ pyridinium chlorochromate on polymer support ${ }^{14}$ or on alumina,${ }^{15}$ and other halochromates such as pyridinium fluorochromates. ${ }^{16}$ However, most of these

\footnotetext{
*To whom correspondence should be addressed.
}

reagents suffer from some disadvantage such as instability, difficulty of preparation, requirement of a large excess of reagent, hygroscopicity, low selectivity or cost of use. In addition, many of the existing methods employing these reagents become impractical for operation on a scale larger than submolar.

This paper describes an investigation of the reactivity and scope of a new chromium(VI) oxidation agent, potassium chlorochromate, $\mathrm{KCrClO}_{3}$ (KCC). The use of this compound, particularly in conjunction with 18-crown-6, for the oxidation of alcohols has previously been described by O'Brien. ${ }^{17}$ Mitzner et al. have investigated the reaction with ethylene glycol. ${ }^{18}$ To our knowledge, no key synthetic applications of this reagent have appeared in the literature.

$\mathrm{KCC}$ is a reddish-orange solid consisting of monoclinic crystals without water of hydration. It hydrolyzes readily when dissolved in water and decomposes slowly upon heating to about $150^{\circ} \mathrm{C}$. Its thermal behaviour has been investigated by Foster and Hambley. ${ }^{19}$ However, KCC is not hygroscopic and under normal room temperature conditions is perfectly stable. Thus, no sign of decomposition was detected for a sample kept on the shelf for more than 6 years. $\mathrm{KCC}$ is prepared simply by dissolving potassium dichromate in ca. $6 \mathrm{M} \mathrm{HCl}$ at $70^{\circ} \mathrm{C}$ and isolating the precipitated 
product after cooling. The IR spectrum $(\mathrm{KBr})$ showed absorptions at 965,950 and $916 \mathrm{~cm}^{-1}$, in agreement with previously reported data. ${ }^{21}$ Other methods of preparation involving chromyl chloride have been described in the literature. ${ }^{22} \mathrm{KCC}$ is very soluble in acetone (ca. $45 \mathrm{~g} / 100 \mathrm{ml}$ ), in acetonitrile (ca. $30 \mathrm{~g} / 100 \mathrm{ml}$ ), in ethyl acetate (ca. $14 \mathrm{~g} / 100 \mathrm{ml}$ ), in dimethyl sulfoxide (ca. $50 \mathrm{~g} / 100 \mathrm{ml}$ ) and in $N, N$-dimethylformamide, (DMF). ${ }^{*}$ Solutions in acetone and acetonitrile appear to be fairly stable, particularly if stored cold. KCC is not appreciably soluble in methylene chloride, benzene or hexane.

\section{Results and discussion}

Most experiments were carried out using solutions of $\mathrm{KCC}$ in acetone, but acetonitrile, ethyl acetate and DMF or slurries in dichloromethane have also been used successfully. Acetone was chosen as the standard solvent for reactions, not necessarily because it may give the optimum yield, but to ensure homogeneous reaction conditions and because acetone is an inexpensive and convenient industrial solvent that gives fewer disposal problems than for example halogenated solvents. As illustrated by the results presented below, comparable or better results can often be obtained using other solvents.

A series of alcohols was oxidized by KCC. The reactions in acetone were generally accomplished merely by adding $\mathrm{KCC}$ as a solid or as a solution in acetone to a stirred solution of the substrate in acetone or vice versa. The reactions were normally exothermic. It was therefore important to ensure a controlled addition, particularly in large-scale experiments. Some representative results are shown in Table 1. Yields were determined by GLC or were those of the pure distilled or crystallized products.

Saturated primary alcohols were oxidized to the corresponding aldehydes, but only in low yields. The best results were generally obtained with acetone or dichloromethane as solvent. When monitoring the rate of formation of aldehyde, we initially observed an accumulation of

\footnotetext{
${ }^{*}$ Dissolution of KCC in DMSO and DMF is an exothermic process. $10 \mathrm{~g}$ could initially be dissolved in $10 \mathrm{ml}$ of DMF, but upon standing a yellow precipitate was formed, identified as $\mathrm{K}_{2} \mathrm{CrO}_{4}$ by its IR spectrum: 958 , $940,910,890,770 \mathrm{~cm}^{-1}$.
}

the product. After reaching a maximum, the amount of aldehyde started to decrease and eventually it disappeared. The reason for this behaviour is uncertain but may be due to polymerization, while no carboxylic acids or esters could be detected in the reaction mixtures. Although a marked increase in the yield of aldehydes is observed if anhydrous sodium bicarbonate is added to the reaction mixtures, KCC appears to be a less suitable reagent for the oxidation of saturated primary alcohols.

KCC oxidized saturated secondary alcohols to the corresponding ketones in high yields (Table 1, entries 4-11) in solvents such as acetone, dichloromethane, acetonitrile or ethyl acetate. Good yields were generally obtained from primary and secondary allylic alcohols (entries 1217); thus, verbenol was quantitatively converted to verbenone and was isolated in $80 \%$ yield. This reaction was also performed on a two molar scale, yielding $92 \%$ of isolated verbenone. Isomerically pure nerol was converted to citral $(74 \%)$, illustrating that some cis-trans isomerization of double bonds may take place in the course of the reaction (entry 14). A similar type of reactivity has been reported for PCC. ${ }^{5}$

Oxidative transformations of tertiary allylic alcohols with $\mathrm{PCC}$ and $\mathrm{CrO}_{3}$ have been extensively investigated. ${ }^{23} \mathrm{We}$ observed the same type of reactivity for KCC. Thus, reaction of linalool afforded the transposed aldehyde, citral, in $73 \%$ yield (entry 16). Cinnamyl alcohol gave only $46 \%$ of the expected product, cinnamaldehyde, together with $15 \%$ of benzaldehyde (entry 17 ). This type of oxidative allylic cleavage reaction with di-tert-butylchromate has been reported by Suga et al. ${ }^{24}$

The oxidation of homoallylic systems gave less satisfactory results. Oxidation of 3-methyl-3-buten-1-ol gave only intractable material (entry 18), and isopulegol upon oxidation afforded only $47 \%$ of isolated isopulegone together with ca. $10 \%$ of pulegone (entry 19), supporting the view that KCC may facilitate double bond isomerization.

Benzylic alcohols were oxidized smoothly to the corresponding carbonyl compounds in good yields (entries 20 to 25). Benzyl alcohol was oxidized to benzaldehyde in $67 \%$ isolated yield; the product was not oxidized further to benzoic acid upon prolonged treatment with KCC. $\alpha$-Cyclopropylbenzyl alcohol (entry 25) gave the ex- 
Table 1. Oxidation of selected alcohols with potassium chlorochromate.

\begin{tabular}{|c|c|c|c|c|}
\hline Entry & Substrate (Solvent) ${ }^{d}$ & $\begin{array}{l}\text { Molar } \\
\text { Ratio }\end{array}$ & Time/h & Products, yield $/ \%^{a}$ \\
\hline 1 & 1-Hexanol $\left(\mathrm{CH}_{2} \mathrm{Cl}_{2}\right)$ & $1: 3$ & 60 & Hexanal, $47^{b}$ \\
\hline 2 & - & $1: 3$ & 60 & $-\quad 47^{b}$ \\
\hline 3 & $\left(\mathrm{CH}_{2} \mathrm{Cl}_{2} / \mathrm{NaCO}_{3}\right)$ & $1: 3$ & 60 & $72^{b}$ \\
\hline 4 & 2-Octanol $\left(\mathrm{CH}_{2} \mathrm{Cl}_{2}\right)$ & $1: 1$ & 10 & 2-Octanone, $82^{b}$ \\
\hline 5 & $-\quad\left(\mathrm{CH}_{2} \mathrm{Cl}_{2}\right)$ & $1: 3$ & 8 & $-80^{b}$ \\
\hline 6 & $10.2<=21$ & $1: 3$ & 10 & $66^{b}$ \\
\hline 7 & $\left(\mathrm{CH}_{3} \mathrm{CN}\right)$ & $1: 3$ & 4 & $90^{b}$ \\
\hline 8 & (DMF) & $1: 3$ & 150 & $61^{b}$ \\
\hline 9 & 4-tert-Butylcyclohexanol & $1: 1.5$ & 3 & 4-tert-Butylcyclohexanone, 84 \\
\hline 10 & Menthol & $1: 3$ & 3 & Menthone, 85 \\
\hline 11 & Borneol & $1: 2$ & 2 & Camphor, $74^{c}$ \\
\hline 12 & Verbenol & $1: 2$ & 0.5 & Verbenone, $80(999)$ \\
\hline 13 & - & $1: 1$ & 2 & $82\left(92^{\circ}\right)$ \\
\hline 14 & Nerol & $1: 2$ & 2 & Citral, 74 \\
\hline 15 & Pulegol & $1: 2$ & 3 & Pulegone + Isopulegone, 55 \\
\hline 16 & Linalool & $1: 2$ & 6 & Citral, 73 \\
\hline 17 & Cinnamyl alcohol & $1: 2$ & 1 & Cinnamaldehyde, 45; Benzaldehyde, 15 \\
\hline 18 & 3-Metyl-3-buten-1-ol & $1: 2$ & 2 & Intractable products \\
\hline 19 & Isopulegol & $1: 2$ & 1 & Isopulegone 47; Pulegone, 10 \\
\hline 20 & Benzyl alcohol & $1: 2$ & 3 & Benzaldehyde, 67 \\
\hline 21 & Benzyl alcohol & $1: 1$ & 20 & Benzaldehyde, $84^{b}$ \\
\hline 22 & 4-Methoxybenzyl alcohol & $1: 2$ & 1 & 4-Methoxybenzaldehyde, 67 \\
\hline 23 & 4-Chlorobenzyl alcohol & $1: 2$ & 1 & 4-Chlorobenzaldehyde, $81^{c}$ \\
\hline 24 & 1-Phenylethanol & $1: 2$ & 6 & Acetophenone, 85 \\
\hline 25 & $\alpha$-Cyclopropylbenzyl alcohol & $1: 1.5$ & 6 & $\begin{array}{l}\text { Cyclopropyl phenyl ketone, } 55 \text {; di( } \alpha \text { - } \\
\text { cyclopropylbenzyl) ether, } 15\end{array}$ \\
\hline 26 & Benzoin & $1: 2$ & 6 & Benzil, $71^{c}$ \\
\hline 27 & Mandelic acid & $1: 2$ & 5 & Benzaldehyde, 89 \\
\hline 28 & Methyl mandelate & $1: 1.5$ & 6 & $\mathrm{PhCOCOOCH}_{3}, 82$ \\
\hline 29 & $\mathrm{PhCOCOOH}$ & $1: 2$ & 24 & No reaction \\
\hline
\end{tabular}

a Unless stated otherwise, yields were of distilled or recrystallized products of at least $95 \%$ purity by GLC. ${ }^{b}$ Yields determined by GLC relative to an internal standard. ${ }^{c}$ Recrystallized product. ${ }^{d}$ Unless otherwise indicated the solvent is acetone. ${ }^{~}$ Yield in a 2 molar scale preparative experiment.

pected ketone in $55 \%$ yield, together with $15 \%$ of a by-product identified as $\operatorname{di}(\alpha$-cyclopropylbenzyl) ether.

That $\mathrm{KCC}$ is a relatively mild oxidation agent was illustrated by the reaction with benzoin (entry 26 ), forming benzil in $71 \%$ yield with no sign of bond cleavage products. On the other hand, decarboxylation took place upon oxidation of $\alpha$ hydroxy acids. Thus, mandelic acid was converted to benzaldehyde in $89 \%$ yield. In contrast to this result, methyl mandelate was transformed into methyl benzoylformate (entry 28), whereas benzoylformic acid showed no sign of reactivity (entry 29). The mechanistic aspects of the KCC- promoted oxidation are currently being subjected to a closer investigation.

A 1:2 or 1:3 molar ratio of substrate to reagent was generally used to ensure ready and complete conversion to the product. However, a 1:1 molar ratio often gave roughly the same yield for only slightly longer reaction times. This was demonstrated for 2-octanol and benzyl alcohol in dichloromethane (entries 4 and 21) and for verbenol in acetone (entry 13).

In order to drive the reaction to completion, it was essential to use KCC in high concentrations. Thus, in GLC experiments with KCC concentrations in the range 3-5\%, complete conversion 
was often difficult to achieve. With the concentration increased to $20-40 \%$, the reactions proceeded smoothly to completion.

Conclusion. KCC is a selective, inexpensive and readily available reagent suitable for oxidation of saturated secondary alcohols, primary and secondary allylic alcohols and benzylic alcohols to the corresponding carbonyl compounds. The reactions can be carried out in a variety of solvents, for example acetone, dichloromethane or acetonitrile, with only a modest excess of the oxidant. The results obtained for the oxidation of saturated primary and homoallylic alcohols show that $\mathrm{KCC}$ is not a very useful reagent for the transformation of these compounds. However, $\mathrm{KCC}$ is potentially an attractive alternative to PCC. Being an acidic reagent, $\mathrm{KCC}$ also possesses some of the same limitations as PCC, such as not being applicable in the presence of acid-sensitive substrated or products. Upon aldehyde formation, little or no over-oxidation to acids can be detected. However, double bond isomerizations may take place.

\section{Experimental}

General. ${ }^{1} \mathrm{H}$ NMR spectra were recorded on a Varian EM-390 or a JEOL FX-100 NMR spectrometer. IR spectra were recorded on a PerkinElmer 257 spectrophotometer, and mass spectra on a AEI MS-902 spectrometer at $70 \mathrm{eV}$. GLC measurements were performed on a Varian 3700 gas chromatograph equipped with a BP-1 capillary column $(25 \mathrm{~m})$ or a packed column of $5 \%$ OV-17 (1.6 m).

Potassium chlorochromate, KCC was prepared from $\mathrm{K}_{2} \mathrm{Cr}_{2} \mathrm{O}_{7}$ and $\mathrm{HCl}$ according to the method described by Herzog et al. ${ }^{25}$

Oxidation of alcohols with KCC. General procedure. To a stirred solution containing $35 \mathrm{mmol}$ of the alcohol dissolved in $25 \mathrm{ml}$ of acetone placed in a reaction flask equipped with a reflux condenser and an effective stirrer, was added 6.1-17.5 g (35-100 mmol) of solid KCC in small portions (the reaction is exothermic).

An alternative method is dropwise addition of $35-100 \mathrm{mmol}$ of a $2 \mathrm{M}$ solution of $\mathrm{KCC}$ in acetone to $35 \mathrm{mmol}$ of the substrate in $5-10 \mathrm{ml}$ of acetone. Yet another procedure is dropwise addition of $35 \mathrm{mmol}$ of the alcohol, either neat or as a solution in acetone, to $6.1-17.5 \mathrm{~g} \mathrm{(35-100} \mathrm{mmol})$ or $\mathrm{KCC}$ in $15-45 \mathrm{ml}$ of acetone.

As a result of gelation and precipitation of inorganic material, it was sometimes necessary to add additional small amounts of acetone to the reaction mixture. The resulting mixture was stirred until GLC analysis revealed that all substrate was consumed. $100 \mathrm{ml}$ of hexane (or methylene chloride, chloroform or benzene) was added and after stirring for an additional hour the resulting solution was filtered and concentrated under reduced pressure. In order to remove all the inorganic material the solution was filtered through a short column of silica gel or florisil. The crude product was distilled under reduced pressure or recrystallized from an appropriate solvent. The identities of the pure products were confirmed by comparison of their spectroscopic properties (IR, NMR and MS) with those of authentic samples and by GLC co-injection.

Oxidation of cinnamyl alcohol. To a solution of $5.0 \mathrm{~g}(37.3 \mathrm{mmol})$ of cinnamyl alcohol in $50 \mathrm{ml}$ of acetone was added portionwise $13.0 \mathrm{~g}$ (74.5 $\mathrm{mmol})$ of KCC. Owing to gelation it was necessary to add an additional $10 \mathrm{ml}$ of acetone. The reaction mixture was stirred for $50 \mathrm{~min}$ and $100 \mathrm{ml}$ of hexane was added. Filtration, evaporation and distillation under reduced pressure gave two products, benzaldehyde $(0.58 \mathrm{~g}, 5.47 \mathrm{mmol}$, $15 \%$ ) with b.p. $61-65^{\circ} \mathrm{C}$ at $8 \mathrm{mmHg}$, and cinnamaldehyde $(2.23 \mathrm{~g}, 45 \%)$ with b.p. 108 $114^{\circ} \mathrm{C}$ at $8 \mathrm{mmHg}$.

Oxidation of $\alpha$-cyclopropylbenzyl alcohol. To a solution containing $5.0 \mathrm{~g}(33.7 \mathrm{mmol})$ of $\alpha$-cyclopropylbenzyl alcohol in $5 \mathrm{ml}$ of acetone was added dropwise $35 \mathrm{ml}(70 \mathrm{mmol})$ of a $2 \mathrm{M}$ solution of $\mathrm{KCC}$ in acetone. The reaction mixture was then stirred for $6 \mathrm{~h}$. Addition of hexane, filtration and evaporation of the solvent, followed by distillation under reduced pressure, gave $2.71 \mathrm{~g}(55 \%)$ of cyclopropyl phenyl ketone, b.p. $118-120 \%$ at $11 \mathrm{mmHg}$. IR (neat): 3080,3060 , $3010,1660,1600,1580,1495,1450,1420,1380$, $1305,1220,1180,1160,1090,1040,1030,990$, $935,870,820,785,740,700,690 \mathrm{~cm}^{-1} .{ }^{1} \mathrm{H}$ NMR (100 MHz, $\mathrm{CDCl}_{3}$, TMS): $\delta$ 0.85-1.10 (m, 2H), 1.10-1.35 (m, 2H), 2.5-2.8 (m, 1H), 7.1-7.55 $(\mathrm{m}, 3 \mathrm{H}), 7.9-8.1(\mathrm{~m}, 2 \mathrm{H}) \mathrm{ppm}$. MS [m/e (\% rel. 
int.)]: $146\left(\mathrm{M}^{+}\right)(48), 145(9), 117(3), 105(100)$, 77 (37), $69(8), 58(9), 51(10)$.

A by-product, $0.76 \mathrm{~g}(15 \%)$, was distilled at $170^{\circ} \mathrm{C}$ and $11 \mathrm{mmHg}$ and identified as di $(\alpha$-cyclopropylbenzyl) ether on the basis of its characteristic spectroscopic properties. IR (neat): 3080 , $3060,3020,3000,2970,2925,2860,1600,1580$, $1495,1450,1430,1380,1340,1305,1265,1225$, $1200,1170,1155,1080,1055,1025,995,970,910$, $855,840,770,750,700 \mathrm{~cm}^{-1} .{ }^{1} \mathrm{H}$ NMR $(100 \mathrm{MHz}$, $\left.\mathrm{CDCl}_{3}, \mathrm{TMS}\right): \delta \quad 0.05-0.70(\mathrm{~m}, 8 \mathrm{H}), 0.95-1.35$ $(\mathrm{m}, 2 \mathrm{H}), 3.32(\mathrm{~d}, J=7.8 \mathrm{~Hz}, 2 \mathrm{H}), 7.15-7.45$ (broad singles, 10H) ppm. ${ }^{13} \mathrm{C}$ NMR $(25 \mathrm{MHz}$, $\mathrm{CDCl}_{3}$, TMS, proton decoupled): $\delta 2.65,4.63$, $18.47,82.85,127.01,127.49,128.27,142.07 \mathrm{ppm}$. MS [m/e (\% rel. int.)]: $278\left(\mathrm{M}^{+}\right)(0.2), 147(16)$, 132 (27), 131 (100), 91 (16), 77 (4).

Oxidation of verbenol. KCC (390 g) was dissolved in $1000 \mathrm{ml}$ of acetone in a flask, and a solution of $304 \mathrm{~g}(2.0 \mathrm{~mol})$ of verbenol in $300 \mathrm{ml}$ of acetone was added with stirring over a $1 \mathrm{~h}$ period. The resulting reaction mixture was stirred for $2 \mathrm{~h}$ and $1500 \mathrm{ml}$ of hexane was added. After stirring for a further $1 \mathrm{~h}$ the mixture was filtered, the solvent evaporated under reduced pressure and the crude product distilled (b.p. $98-100^{\circ} \mathrm{C}$ at $10 \mathrm{mmHg})$, yielding $276 \mathrm{~g}(1.84 \mathrm{~mol}, 92 \%)$ of pure verbenone.

\section{References}

1. (a) House, H. O. Modern Synthetic Reactions, 2nd ed., Benjamin, New York 1972; (b) Wiberg, K. B. Oxidation in Organic Chemistry, Academic Press, New York 1965; (c) Lee, D. G. In: Augustine, R. L., Ed., Oxidation, Marcel Dekker, New York 1969; (d) Hartford, W. H. and Darrin, M. Chem. Rev. 58 (1958) 1; (e) Lala, A. K. and Kulkarni, A. B. J. Scient. Ind. Res. 34 (1975) 605; (f) Westheimer, F. H. Quart. Rev. 48 (1948) 419; (g) Waters, W. A. Quart. Rev. 48 (1948) 277; (h) Cainelli, G. and Cardillo, G. Chromium Oxidation in Organic Chemistry, Springer, Heidelberg 1984.

2. Bowers, A., Halsall, T. G., Jones, E. R. H. and Lemin, A. J. J. Chem. Soc. (1953) 2548.

3. Poos, G.-I., Arth, G. E., Beyler, R. E. and Sarett, L. H. J. Am. Chem. Soc. 70 (1948) 3827.

4. Collins, J. C., Hess, W. W. and Frank, F. J. Tetrahedron Lett. (1968) 3363.

5. Corey, E. J. and Suggs, J. W. Tetrahedron Lett. (1975) 2647.
6. (a) Corey, E. J. and Schmidt, G. Tetrahedron Lett. (1979) 399; (b) Piancatelli, G., Scettri, A. and D'Auria, M. Synthesis (1982) 245; (c) Coates, W. M. and Corrigan, R. Chem. Ind. 44 (1969) 1594; (d) Still, W. C. and Galynker, I. J. Am. Chem. Soc. 104 (1982) 1774.

7. Guziec, F. S. and Luzzio, F. A. J. Org. Chem. 47 (1982) 1789.

8. Santaniello, E., Milani, F. and Casati, R. Synthesis (1983) 749.

9. Lopez, C., Gonzalez, A., Cosio, F. P. and Palomo, C. Synth. Commun. 15 (1985) 1197.

10. Guziec, F. S. and Luzzio, F. A. Synthesis (1980) 691.

11. Rao, C. G., Radhakrishna, A. S., Bali Singh, B. and Bhatnagar, S. P. Synthesis (1983) 808.

12. Huang, X. and Chan, C.-C. Synthesis (1982) 1091.

13. Firouzabadi, H., Sardarian, A. and Gharibi, H. Synth. Commun. 14 (1984) 89.

14. (a) Frechet, M. J., Warnock, J. and Farrall, M. J. J. Org. Chem. 43 (1978) 2618; (b) Frechet, M.J., Darling, P. and Farrell, M. J. J. Org. Chem. 46 (1981) 1728.

15. Cheng, Y.S., Liu, W. L. and Chen, S. Synthesis (1980) 223.

16. (a) Bhattacharjee, M. N., Chaudhuri, M. K., Dasgupta, H. S. and Roy, N. Synthesis (1982) 588; (b) Nonaka, T., Kanemoto, S., Oshima, K. and Nozoki, H. Bull. Chem. Soc. Jpn. 57 (1984) 2019.

17. O'Brian, A. B. Ph.D. Thesis, Part II: Oxidation of Primary and Secondary Alcohols by $\mathrm{KCrClO}_{3}$, 1981; see Chem. Abstr. 95 (1981) 61692.

18. Mitzner, R. and Sommer, R. Z. Chem. 19 (1979) 305.

19. Foster, J. J. and Hambly, A. N. Aust. J. Chem. 29 (1976) 2137; Ibid. 30 (1977) 251.

20. (a) Helmholz, L. and Foster, W. R. J. Am. Chem. Soc. 72 (1950) 4971; (b) Haig, G. P., Richardson, D. D. and Coburn, N. C. Inorg. chem. 3 (1964) 1777; (c) Vanino, L. Handbuch der Präparativen Chemie. I, Ferdinand Enke, Stuttgart 1925, p. 321.

21. Stammreich, H., Sala, O. and Kawai, K. Spectrochim. Acta. 17 (1961) 1141.

22. Sisler, H. H. Inorg. Synth. 2 (1946) 208.

23. (a) Dauben, W. G. and Michno, D. M. J. Org. Chem. 42 (1977) 682; (b) Babler, J. H. and Coghlan, M. J. Synth. Commun. 6 (1976) 469; (c) Sundararaman, P. and Herz, W. J. Org. Chem. 42 (1977) 806; Ibid. 813.

24. Suga, T., Kihara, K. and Matsura, T. Bull. Chem. Soc. Jpn. 38 (1965) 893.

25. Herzog, S., Gustav, K. and Strahle, J. Handbuch der Präparative Anorganischen Chemie. II, Ferdinand Enke, Stuttgart 1981, p. 1526.

Received October 9, 1986. 